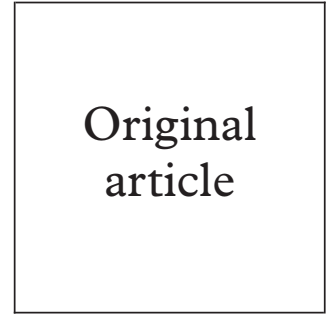

\title{
Rapid detection of glycoprotein G gene for the diagnosis and typing of herpes simplex virus infection in genital herpes
}

\author{
X F Fang, B Song, Y Y Tu, J Z Tong, J L Faul, H Bai
}

Objective: To develop a new, rapid, and convenient technique for the diagnosis and typing of
herpes simplex virus (HSV) in genital herpes (GH). Methods: Using samples from skin vesicle fluid and urogenital mucosal swabs of subjects with $\mathrm{GH}$, conventional polymerase chain reaction (PCR) (directed to polymerase gene: PCRpG) were compared with a newly developed PCR (directed to HSV glycoprotein gene: PCRgG). Both PCR methods were compared with virus isolation culture (VI) with indirect immunofluorescent staining (IIF).

Results: 80 samples from $40 \mathrm{GH}$ patients (25 males) were tested. Positive results were seen in $52.5 \%$ (42/80) using PCRgG compared with $40 \%$ (32/80) by VI. Most of PCRgG positive samples (95.1\%) were caused by HSV-2 infection. In samples from healing lesions, HSV was detected more often by PCRgG, than by VI. The results of typing by PCRgG and IIF were highly consistent.

Conclusion: PCRgG is more sensitive than VI and PCRpG in detecting HSV in urogenital samples from subjects with GH. PCRgG is a convenient technique for the rapid detection and typing of $\mathrm{GH}$.

(Sex Transm Inf 1999;75:396-397)

Keywords: herpes simplex virus; genital herpes; polymerase chain reaction

\section{Introduction}

The current standard methods of detecting herpes simplex virus (HSV) infection (by virus isolation (VI) and enzyme immunoassay (EIA)) are relatively slow and the results may be non-specific. ${ }^{12}$ We wanted to investigate the effectiveness and convenience of using polymerase chain reaction (PCR) gG to detect HSV infection in subjects with GH. PCR is a popular research method in detecting HSV infection because of its high sensitivity and specificity. ${ }^{3}$ The HSV glycoprotein G gene has the least homology between HSV-1 and HSV $-2^{45}$ and we hypothesised that PCRgG might provide a sensitive and accurate method for the identification of HSV species in genital herpes $(\mathrm{GH})$.

Dermatovenereology,

First Affiliated

Hospital of Sun

Yat-San University of

Medical Science,

Guang Zhou, China

X F Fang

B Song

Y Y Tu

J Z Tong

H Bai

Stanford University Medical Center,

Stanford University,

Stanford, CA, USA

J L Faul

Correspondence to:

Hua Bai, Department of

Dermatovenereology, First

Affiliated Hospital of Sun

Yat-San University of

Medical Sciences, Guang

Zhou, 510080, China

Accepted for publication

22 September 1999

\section{Materials and methods}

Forty subjects (25 males) were recruited from the sexually transmitted diseases (STD) clinic at the affiliated hospital of SUMS, China. All subjects were diagnosed with $\mathrm{GH}$ by standard criteria: STD contact history and the grouping of vesicular lesions; and/or erosion, ulceration and crusting of healing lesions (Chinese Health ministry). ${ }^{6}$ In each subject one sample was taken from genital skin lesions and one from the urethra (cervix and urethra in females). Vesicle fluid was withdrawn by syringe. Cotton swabs were used to sample healing lesions and the urogenital mucosa. Both samples were obtained at one time from each subject (a total of 80 samples).

Vero cells $\left(1 \times 10^{6} / \mathrm{ml}\right)$ (ATCC) were placed in $10 \%$ FBS-1640 medium in 24 well plastic plates with a cover slip and incubated in 5\% carbon dioxide, $37^{\circ} \mathrm{C}$ for 24 hours. Samples
$(0.2 \mathrm{ml})$ were added separately into four wells (two duplicates) and further incubated for another 24-48 hours and observed for cytopathogenic effect.

Thirty two positive cover slips were tested by indirect immunofluorescence (IIF) (monoclonal antibodies: anti-HSVgG1 and mouse anti-HSVgG2, gifts of Dr A C Minson, Department of pathology, division of virology, Cambridge University, were 1:1500 dilution) and negative ones would be continuously observed for a further 14 days.

Samples of viral transport medium $(300 \mu \mathrm{l})$ were tested with $100 \mu \mathrm{l}$ proteinase $\mathrm{K}$-split solution, denatured in $95^{\circ} \mathrm{C}$ for 10 minutes, and stored at $-20^{\circ} \mathrm{C}$ until use. The following primers were used for PCRgG reaction: primer 1 (HSV-1 US sequence, 4351-4370 bp: 5' CCCCCATGCCAAGTATTGGA); primer 2 (HSV-2 HindIII L sequence, 4707-4726 bp, 5' AGCTCCCGCTAAGGACATG), and primer 3 (HSV-1 US sequence, 4818-4837 bp or HSV-2 HindIII L sequence 4901-4922 bp, 5'-AGACATACGTAACGCACGCT). PCR condition: primer 1 and primer 210 pmol, primer 320 pmol, dNTP $200 \mu \mathrm{m}$, PCR buffer $6 \mu \mathrm{l}$, templet $2 \mu \mathrm{l}$, adding distilled water to 30 $\mu$. The solution mix was heated to $94^{\circ} \mathrm{C}$ for 3 minutes and Taq polymerase $1.5 \mu \mathrm{l}$ was added. The PCR reaction was cycled at $94^{\circ} \mathrm{C}(45$ seconds), $58^{\circ} \mathrm{C}$ (45 seconds), and $72^{\circ} \mathrm{C}$ (1 minute) (for 35 cycles) and completed with $72^{\circ} \mathrm{C}$ for 5 minutes. PCR products were run on $2 \%$ agarose gel. Six gradient diluted samples $(0.2 \mathrm{ml}$ each) and positive controls (HSV-1 F and HSV-2 333) were used to plaque assay for minimum HSV detected concentration test. 


\section{Results}

CPE was observed in 32/80 samples, and infection by HSV was verified by IIF. In each of 30 samples CPE appeared within 2-3 days and in two samples CPE appeared on the sixth day. The infected HSV-1 cells formed a scattered pattern and most demonstrated ballooned degeneration, while cells infected by HSV-2 were fused into multinucleate giant cells as observed by inversion microscopy and IIF.

The minimum detected sample concentration was $0.75 \mathrm{pfu}$ in HSV-1 and $1.25 \mathrm{pfu}$ in $\mathrm{HSV}-2$. The appearance of HSV-1gG product (216 bp), and HSV-2gG (490 bp) were compared with positive controls from standard strains.

Forty two samples were positive by PCRgG, 30 by both methods. PCR had a higher positive rate than VI in this cohort $\left(\chi^{2}\right.$ test, $\left.\mathrm{p}<0.025\right)$. The sensitivity, specificity, positive and negative predictability of PCR were: $93.8 \%, 75 \%$, $71.4 \%, 94.7 \%$ respectively. If the 12 cases of PCR positive, VI negative samples were assumed to be true positives, these values would be $95.5 \%, 100 \%, 100 \%, 94.7 \%$ respectively. There were 14 inconsistent samples between the two methods. Twelve PCRgG positive, VI negative were also positive by PCRpG. In two samples with VI positive PCRpG negative, one was negative and the other is HSV-2 positive by the PCRpG.

The results of typing by PCR and IIF are presented in table 1 . Two of 42 samples $(4.7 \%)$ were HSV-1 positive. The results of typing were consistent across all methods. Exceptions were HSV-1 and HSV-2 mixed positive samples. Two HSV-1 and HSV-2 positive VI samples were tested by both PCR methods. One was negative by both PCR techniques. The other was only HSV-2 positive by the PCRpG. One sample was positive by both PCRgGs, but was negative by PCRpG.

PCR and VI results in different duration and region are shown in table 2 . No significant difference in vesicle stage or urogenital sampling was found between PCR and VI (Fisher's exact test, $p$ >0.05). In contrast, there was a significant difference between PCRgG and VI in the detection of HSV in the healing stage ( $p$ $=0.03$, Fisher's exact test). The positive rate for the detection of HSV by combining the two methods for skin lesions (47/80) was significantly higher than the positive rate for urogenital swabs (27/80), ( $p<0.01$, Fisher's exact test).

Table 1 Serotypes of detected HSV by PCR and IIF

\begin{tabular}{llllll}
\hline & HSV-1 & HSV-2 & $\begin{array}{l}\text { HSV-1 } \\
+H S V-2\end{array}$ & $\begin{array}{l}\text { Total } \\
\text { positive }\end{array}$ & $\begin{array}{l}\text { Total } \\
\text { negative }\end{array}$ \\
\hline PCR & 2 & 39 & 1 & 42 & 38 \\
IIF & 2 & 28 & 2 & 32 & 48 \\
\hline
\end{tabular}

Table 2 Results according to type of lesion and site of sample

\begin{tabular}{lllll}
\hline & \multirow{2}{*}{ Numbers } & VI (\%) & PCR (\%) & p Value \\
\hline Vesicle lesions & 17 & $16(92.4)$ & $14(82.4)$ & 0.3 \\
Healing lesions & 23 & $5(21.7)$ & $12(52.2)$ & 0.033 \\
Urogenital swabs & 40 & $11(27.5)$ & $16(40)$ & 0.17 \\
\hline
\end{tabular}

\section{Discussion}

Virus isolation is currently the gold standard method for HSV detection in vesicle fluid. However it is slow because it depends on viral culture techniques. ${ }^{17}$ In addition, patients may not attend a physician at the early stage of the disease. Our data show that PCRgG has a higher detection rate in all GH samples, including healing lesions, compared with VI (at least using Vero cells). Our new PCRpG method is more rapid ( $<4$ hours) than VI and promises to enhance the diagnostic efficiency of GH. Moreover, simultaneous quick and accurate typing is also possible. In contrast with PCRpG products, which are of similar size (229 bp and $241 \mathrm{bp}$ for HSV-1 and HSV-2), ${ }^{8}$ the PCRpG products of HSV-1 and HSV-2 differ in size by more than 256 bp (216 bp and $496 \mathrm{bp}$ respectively) and are therefore readily identifiable by standard agarose gel electrophoresis. Typing of HSV is important for our understanding of $\mathrm{GH}$, because previous work has demonstrated genetic differences between HSV-1 and HSV- $2^{4}$ that may account for their distinct epidemiology, clinical features, and prognosis. ${ }^{9}$

The result that HSV was detectable in swabs of urogenital mucosa has three important implications. (i) HSV may infect skin and mucosa simultaneously; (ii) the urogenital mucosa could be a useful sampling site for HSV detection; and (iii) the urogenital mucosa may be an important route for the transmission of HSV. Whether HSV infection makes an individual more susceptible to infection by the same or different HSV types remains to be investigated. Local and generalised susceptibility to co-infection by different strains of HSV may warrant further investigation.

The work was supported by the Chinese Natural Science Fund (3937065)

Contributors: XFF, BS, YYT, and JZT conducted the PCR, VI and IIF, and collected the samples; JLF wrote the paper and performed the statistics; HB designed the PCR primers, conducted and supervised the study, wrote the paper, and performed the statistical analysis.

The authors wish to thank Dr AC Minson (Department of Pathology, Cambridge University, UK) for supplying HSVgG monoclonal antibodies.

1 Somka MJ, Emery L, Munday PE, et al. A comparison of PCR with virus isolation and direct antigen detection for diagnosis and typing of genital herpes. $f$ Med Virol 1998;55:177-83.

2 Schmid DS, Brown DR, Nisenbaum R, et al. Limits in reliability of glycoprotein G-based type-specific serologic assays for herpes simplex virus types 1 and 2. 7 Clin Microbiol 1999;37:376-9.

3 Cone RW, Hobson AC, Brown Z, et al. Frequent detection of genital herpes implex virus DNA by polymerase chain reaction among pregnant women. $¥ A M A$ 1994;272:792-6.

4 McGeock DJ, Dolan A, Donald S, et al. Sequence determination and genetic content of the short unique region in the nation and genetic content of the short unique region in the genome of herpe

5 McGeoch DJ, Moss HW, McNab D, et al. DNA sequence and genetic content of the Hand III region in the short unique component of herpes simplex virus type two genome identification of gene encoding glycoprotein $\mathrm{G}$ and evolutionary comparisons. F Gen Virol 1987;68(Pt1):19-38.

6 Handbook of sexually transmitted disease prevent and treatment. 1 st ed. Nan Jing: Chinese Health Ministry, Jiang Shu Science, 1993.

7 Lakeman FD, White RJ. Diagnosis of herpes simplex virus encephalitis: application of polymerase chain reaction to cerebrospinal fluid from brain-biopsied patients and correlation with disease. F Infect Dis 1995;171:857-63.

8 Pinparinen H, Vaheri V. Genotyping of herpes simplex viruses by polymerase chain reaction. Arch Virol 1991;119: 275-83.

9 Aurelius E. Herpes simplex encephalitis. Early diagnosis and immune activation in acute stage and during long-term follow-up. Scand F Infect Dis (Suppl) 1993;89:3-62. 